\title{
Challenges in EFL Speaking Classes in Turkish Context
}

\author{
Eray Kara \\ Lecturer, Giresun University, School of Foreign Languages, Giresun, Turkey
}

Aycan Demir Ayaz

Research Assistant, METU, Faculty of Education, Ankara, Turkey

Tuğba Dündar

Lecturer, Giresun University, School of Foreign Languages, Giresun, Turkey

\begin{abstract}
This article presents the results of a research study conducted to reveal the reasons of problems Turkish EFL learners face while speaking in L2. In Turkey, there is a perception that although the learners can reach high levels of proficiency in reading, listening, and writing skills, they cannot speak in English like their peers do in other parts of the world. This is substantially concerning as these students have compulsory and selective English courses throughout their ten years of compulsory school education. The problem has formerly been addressed by language learning anxiety, learners' autonomy, deficiencies in teacher education and teachers' development, and lack of material or/and technology in EFL classes (Aydın\&Zengin, 2008; Büyükyavuz\&inal, 2008; Haznedar, 2010; Solak\& Bayar, 2015). This paper directly seeks answers from the students themselves. The study was conducted with 66 students who have to enroll one year of intensive preparatory English class before being accepted to their own departments. A mixed method research design was used to triangulate the findings for higher validity. Quantitative data was analyzed using SPSS 22.0 software package and qualitative data was analyzed using descriptive analysis. The findings showed that students have difficulty in speaking English mainly because of educational and social reasons, while personal reasons are not as influential as the others are.
\end{abstract}

Keywords: Speaking skill failure, educational reasons, social reasons, personal reasons

\section{Introduction}

In a rapidly globalizing world, one must accept how important and vital international communication is. Today, communication is conducted orally and in written form, and also, it is in English as it is the Lingua Franca of our times. Like in many non-English speaking countries, there is a growing need for English in both private and public sectors in Turkey. The private companies look for employees having relevant professional expertise in English and besides, in public areas they get a rise in their salaries when they demonstrate their competence in one of the nationwide foreign language proficiency examinations (Alptekin and Tatar, 2009). In such an atmosphere, learning English becomes inevitable and compulsory for any person who either seeks work or just desires to follow the new developments, innovations and events to keep up with the age in social, economic, scientific and technological aspects (Tosun, 2006). However, it is commonly known that learning a second language (L2) is not a simple and short process. Many problems can prevent learners from beginning that journey. In this case, main difficulties can be handled at personal, educational, and social levels.

\section{Personal Reasons}

In terms of the problems resulted from the learners, the first thing to be noted is anxiety. Anxiety can be the most challenging factor while learning an L2 because most of the learners are not alone in this process; they are in a classroom most of the time. As indicated by Alptekin and Tatar (2009), majority of the EFL learners feel extremely concerned about their oral production when they reach the tertiary level, which causes an anxiety-provoking state when conversing in the L2. 
Conducting a qualitative study, Öztürk and Çeçen (2007) relates foreign language learning anxiety to the learners' lack of self-confidence, which is connected with what they deem to be the insufficient level of English proficiency. On the other hand, as Sevingil (2008) and Zerey (2008), using a standardized L2 speaking anxiety scale,demonstrate, speaking anxiety is not a trait; but it occurs in the presence of the teacher and one's classmates The most frequent source of anxiety for the participants is speaking in class (Alptekin and Tatar, 2009). In addition, findings of a qualitative study catogorizes various types of anxiety as follows according to the answers obtained from the students in high school; i. speaking activities, ii. listening activities, iii. teaching techniques and methods, iv. fear of making mistake, v. learning atmosphere, vi. attitudes of the teacher and vii. tests (Baş,2014, 111).

As significant as anxiety, motivation of the learners of $L 2$ is another aspect to be discussed. Motivation is described as "the combination of effort plus desire to achieve the goal of learning the language plus favourable attitudes toward learning the language" by Gardner (1985, p. 10). Motivation is highly related to the proficiency and achievement of the foreign language learners' in the target language. The study conducted by Zabardast (2014) shows that the university students, most of whom are not highly motivated to learn a foreign language, put some effort to do it only because of personal interest in foreign language and culture or to have a good career in the future. However, as indicated by Demir and Erten (2005) who studied with 4th-grade (age 9-10) and 8th-grade (age 13-14) students, "younger learners have higher motivation, both extrinsic and intrinsic, to learn English than older learners" (Alptekin and Tatar, 2009). Thus, the intention of determining the reasons why the university students lack motivation to learn L2 and seeking answers of the students themselves may help to find solutions to this problem.

In addition to the problems resulting from excessive anxiety or lack of motivation of the learners, different perceptions of teachers and learners could be problematic. Although most instructors and students highlight the significance of students' participation in, especially, listening and speaking lessons, the students' responses reveal that most of the courses are teacher-centred (Akyel and Özek, 2010). They state that while university instructors consider reading and listening skills as the most significant ones for achievement, students reported speaking and listening skills as more important for their academic achievement. Another issue that must be noted is that the students do not have voice on the curriculum development process. Kırıkgöz (2009) states that most EAP (English for Academic Purposes) curriculum designers are not informed about the academic needs of students. Therefore, it can be easily said that to evaluate how effective an EAP curriculum is in meeting the academic needs of students and in providing valuable data for the curriculum development process, it is so important to know the needs analysis of the students' academic context (West, 1994).

In an experimental study, Inal, Evin \& Saracaloglu (2005) demonstrated that learners' academic achievement in English is highly related to their positive attitudes towards the language and its culture as well. The more positive attitudes one has towards the target language culture, the more progress they make. Therefore, the role of culture in shaping the personality cannot be denied. Tosun (2006) states that "your personality, attitudes and behaviours arising from the assimilation of your mother tongue, your culture, and the education you have received so far, your viewpoint of world and events will always rebel against this foreign language imposed on you and will always be in conflict with it"(p.33). In EFL classes, students are exposed to many cultural subjects, which means they are supposed to think and talk about the subjects that are not familiar to them. It is obvious that this makes them feel hesitant to speak in the classroom (Inal et al. 2005).

\section{Educational and Social Reasons}

Among the numerous challenges of improving oral production skills of the EFL learners, the problems related with language teachers cannot be ignored. Since Turkish EFL learners do not have much direct contact with the L2 community, their only chance to practice speaking is the classroom environment. However, teacher-centered language teaching tradition, which is dependent on rote memorization and form-focused instruction are the biggest obstacles to the improvement of that skill in Turkish educational context (Çetintaş, 2010; Haznedar, 2010). In the research study conducted by Haznedar (2010) on 530 primary and secondary state school teachers in a metropolitan city of Turkey, it was revealed that $\% 70$ of language teachers still use rote-memorization and repetition drills which date back to $1960 \mathrm{~s}$. Also, around $\% 75$ of them still prefer grammar-translation method which does not provide any chance of practicing L2 speaking skill at all. Aktaş (2005), on the other hand, suggests language teachers to encourage the learners to speak the language freely without any fear of making mistakes and being criticized by themselves.

According to Haznedar (2010), another problem with language teachers is the lack of information about their language proficiency levels since more than half of the teachers in her study have not taken any language proficiency test; very few 
teachers took IELTS or TOEFL; and around \%30 percent of the teachers took only KPDS (Foreign Language Proficiency Examination for State Employees) which does not test speaking skill and also does not have any international validity. Therefore, it is suggested for the teachers to take an internationally accepted language test and certify their level periodically for their own improvement. Besides, training the language teachers for more recent and effective instructional designs and activities through in-service training programs are among the recommendations of researchers (Işık, 2008; Kızıldağ, 2009) to have more qualified language teachers in Turkey.

Although Ministry of National Education (MoNE) decided on a shift from the traditional form-focused language instruction to meaning and communication-focused one in 2006 (Haznedar, 2010), it is not possible to assert that the new regulations are adopted by each and every teacher. Haznedar (2010) presented that although the teachers know about the new approach to language education, they still continue using the old-fashioned ones such as grammar-translation and memorization. Thus, she suggests training the teachers to encourage them to use contemporary teaching methods. On the other hand, Uysal (2012) advocates that although most language teachers are aware of the communicative methods of language teaching, they cannot make use of them because of practical or institutional reasons such as crowded classes, lack of time to prepare communicative materials, loaded curriculums, technology and equipment deficiencies, and so on. However, it is crucial for language teachers to adopt the new approach as soon as possible to prepare their learners as world-citizens who can freely speak the language to communicate.

Teacher self-efficacy, which can be defined as "teachers' individual beliefs in their capabilities to perform specific teaching tasks at a specified level of quality in a specific situation" (Dellinger, Bobbett, Olivier, \&Ellett, 2008, p.752), is also highly effective on the oral production skills of the EFL learners. According to Demir, Yurtsever, and Çimenli (2015), there is a positive correlation between teacher self-efficacy and their willingness to use communicative activities in language classes. Thus, self-efficacy levels of the teachers are crucial as it is obvious that use of communicative activities by teachers will lead to progress in speaking skills of the learners. Finally, communicative activities can help the teachers expand their own oral production abilities as well (Uysal, 2012).

Among the challenges teachersface, the most important ones are material selection and physical environment for language learning. In Turkey, there are many publishers/publishing houses importing text books for schools, though, teachers at public schools do not have the freedom of selecting their own course books. MoNE provides books for all students, and English text books are prepared by group of professionals, which may be seen to cause problems in EFL classes. According to Hutchinson (1987) a good material should have one or more interesting texts, enjoyable activities and opportunities for learners by providing their potential knowledge and skills. It is known that good materials help both teachers and learners to maximize the chances of learning, as they are the source of the nature of language and learning process (Kizildag, 2009). However, she emphasizes with the findings of her study that the course books are poorly developed and supplementary materials lack in meeting the need for communication. Likewise, YIImaz (2008) underlines the fact that EFL textbooks used in Turkish schools are mainly grammar and reading based, and lack in supplying environment for verbal communication. As Buyukyavuz\&inal (2008) state, English language teaching in Turkey has problems stemming from shortage of English language teachers, crowded classrooms and lack of instructional materials.

Starting from 2005, MoNE has made radical changes in teaching programs as a reflection of the globalization process. Globalization is a highly complex process that has made a considerable impact on the multidimensional aspects of societies at various levels, including language policies of many countries. These policy changes emphasized the need for speaking ability in students. Textbooks were designed accordingly. Then, it was followed by DynEd@, which is a learner centered communicative computer module, assisting students for self-study. The module was designed by professionals in language teaching, companies like DynED International Inc., Oxford University Press, Longman, Prentice Hall, BBC, Stanford University, Apple, IBM, SONY, and NEC (Kizildağ, 2009). In spite of the efforts and good intentions in mind, DynEd module is no longer used in classes as for the facts that all schools do not have a computer laboratory, or Internet access.

Finally, it is an undeniable fact that society in which a person grows up shapes the attitudes of learners towards learning a foreign language as well as their traits and educational environment. Learning cannot be thought sperately; it occurs when learners participate in the learning process and interact with their environment (Yurtsever-Bodur, 2015). The success in learning a foreign language correlates with the structure of the society that must be taken into account (Işık, 2008). That is why, it can be easily understood when learners claim that they can not learn a language when there are no people speaking English around them or when their parents do not know English( Yurtsever-Bodur, 2015). Besides, most learners need some other kind of motivations to struggle for learning a languge. In a society they live in, if they need English 
fortheirprofessionalcareer, it becomessomethingmore beneficial andworthlearning. Therefore, learners need to adopt the idea that English is going to be necessary and contribute to their life (Yurtsever-Bodur, 2015).

\section{Aim and the Research Questions}

1. What are the participants' perceptions on the social reasons for their failure in learning speaking in English?

2. What are the participants' perceptions on the personal reasons for their failure in learning speaking in English?

3. What are the participants' perceptions on the educational reasons for their failure in learning speaking in English?

4. Is there any meaningful relationship among the participants' social, personal, and educational reasons and their individual characteristics such as (a) family income and (b) parental knowledge of English?

\section{Methodology}

\section{Setting and Participants}

The first part of the scale in this study was designed to attain demographic information of the participants. A close investigation of that part showed that 21 participants were males (32.3\%) while 44 of them were females (67.7\%); one participant did not provide sex information. Most of the participants, who were $53(82.8 \%)$ in number, were young adults between the ages of 18 and $21 ; 7$ of them (10.9\%) were between 22 and 25 ; and only 4 participants $(6.3 \%)$ were 26 and above. Regarding the educational background of their mothers, participants reported that 23 of them (34.8\%) were primary school graduates while only $13(19.7 \%)$ were university graduates. The findings for the fathers' educational background were also similar, $21(31.8 \%)$ being primary school graduates and only $9(13.6)$ fathers being university graduates. The numbers of uneducated parents were also noteworthy (9 mothers, 4 fathers). 51 students $(77.3 \%)$ stated owning a house while 15 of them (22.7\%) rented their house. With respect to their monthly income, majority of the participants $(61.5 \%)$ stated that they had an income between 1001-3000 Turkish Liras per month while 12 of them (18.5\%) had a monthly income under 1000 Turkish Liras (almost half of the minimum wage).

This research study was conducted in Black Sea Region and therefore, the participants who mostly lived in Black Sea Region (27\%) until the age of 13 outnumbered the others. 11 participants (17.5\%) reported spending this time in the cities in Marmara Region while only 1 participant (1.6\%) had lived in Eastern Anatolia from birth to the age of 13 . There were also 3 participants (4.8\%) who were abroad during that period. Finally, the analysis of the parents' knowledge of English revealed that only 5 of the mothers $(7.6 \%)$ and 7 of the fathers $(10.6 \%)$ knew English, which was a predictable but sad result. These findings can be viewed in detail in Table 1 above.

\section{Data Collection}

The data was collected from 66 preparatory school students at Giresun University, in 2016-17 academic years. All of the students enrolled in the program were included in the sampling; none stated an excuse to be excluded. A 54 item questionnaire, developed by Yurtsever-Bodur and Arikan(2015) was used as data collection tool. The questionnaire has three sub-categories as social, personal and educational reasons for failing to learn a new language. In order to validate the findings, a follow up interview wasdesigned for the problematic areas specified during the analysis of the data. First, the problem areas were addressed and five semi-strucutred interview questions were written. Second, the questions were checked by four experts in the field of educational sciences and language teaching. As a third step, the questions were piloted with a group of ten students. Last, the interviews were planned and made with 8 students from the faculty of administration. The findings of the both tools were compared and presented in the following section.

\section{Data Analysis\&Findings}

In this section, findings of the study will be presented starting with an overall descriptive analysis of social, personal, and educational reasons. Then, the results for each research question will be clarified in detail. 
Table 2: Overall descriptive analysis of social, personal, and educational reasons

\begin{tabular}{llll}
\hline & N & Mean & SD \\
\hline Social reasons & 66 & 3.03 & .739 \\
Personal reasons & 66 & 2.65 & .902 \\
Educational reasons & 66 & 3.28 & .910
\end{tabular}

Descriptive statistics showed that the participants mostly believed in the negative effects of educational reasons (mean = $3.28, S D=.910$ ) on their failure in speaking English. Then, they attributed their problems in oral production to social reasons with a mean value of $3.03(S D=.739)$. As might be expected, personal reasons were the last to be perceived as the sources of their problems in learning speaking English (mean $=2.65, S D=.902$ ). The results can be viewed in Table 2 .

Research Question 1: What are the participants' perceptions on the social reasons for their failure in learning speaking in English?

To investigate the social reasons behind the participants' failure in speaking English, they were asked to respond to 10 items below. They were required to rate their agreement and disagreement on the items from 5 (strongly agree) to 1 (strongly disagree), and then descriptive analysis were conducted to see the results. To present a clearer picture of their agreement and disagreement positions, the researchers preferred interpreting "strongly agree" and "agree" scores under one title and "strongly disagree" and "disagree" collected together under another. As of now, agreement refers to both "strongly agree" and "agree", and disagreement refers to "strongly disagree" and "disagree" in the scale.

According the results of the descriptive analysis, the participants agreed on item 2 stating that "If my mother or my father had known English, I would have learnt speaking English better, "with the highest positive agreement percentage of 74.2 (mean $=4.19, S D=1.098$ ). It was followed by the first item stating that "If there had been English programs on TV and radio (original or with English subtitles), I would have learnt speaking English better." (72.8\%), with a mean score of 4.03, $(S D=.999)$; and "If there had been English speakers around me, I would have learnt speaking English better." also scored quite high in terms of the percentage of agreement on it $(72.7 \%$, mean $=4.14, S D=1.180)$. It can be interpreted from these results that the participants regarded the low amount of input that come from their parents, significant others around them, and TV or other information tools as the main social reasons for their failure in speaking English.

On the other hand, they showed strongest disagreements with the items "I couldnot learn speaking English because my mother or my father motivated me to go to other courses (football, guitar etc.) instead of English courses." ( $74.2 \%$, mean $=$ $1.96, S D=1.323$ ) and "I could not learn speaking English because I think that we would be dominated by another country if we learnt English. " $(74.2 \%$, mean $=1.84, S D=1.301)$. These findings suggest that they were not encouraged to sacrifice speaking English for an interest in another area, or they do not have any nationalistic perspective on learning English.

Research Question 2: What are the participants' perceptions on the personal reasons for their failure in learning speaking in English?

In this research study, the items from 11 to 28 sought to see the participants' perceptions on the effects of personal reasons on their speaking achievement. A close investigation of the percentages and mean scores revealed a 90.9 percent agreement on the item stating that "If I had had the chance to go abroad, I would have learnt speaking English better." (mean $=4.59, S D=.803$ ). It clearly shows that the chance of going abroad is a significant motivator for them to speak English. The participants also showed positive agreement on the fourteenth item admitting that "I could not learn speaking English because I did not spend enough time to learn English." with a percentage of 53.1 (mean $=3.55, S D=1.294$ ).

High percentages of disagreements were observed subsequently (from high to low percentages) for the items of "I could not learn speaking English because I think speaking English will not contribute anything to my life." $(80.3 \%$, mean $=1.78$, $S D=1.271)$, "I did not learn speaking English because I have always wanted to speak another language." (78.8\%, mean $=1.90, S D=1.261$ ), and "I did not think speaking English would provide job opportunities for me. That's why I did not learn it." $(66.6 \%$, mean $=2.00, S D=1.322)$. It can be inferred from the results that the participants do not ignore the contributions 
of English to their life and future career. They also do not show a preference for another foreign language than English since they are potentially aware of the advantages of speaking it.

To provide an overall impression of the analysis of personal reasons, it can be advocated that the learners mostly reported disagreement with the items, which signifies that they do not tend to blame themselves for their failure in speaking English.

Research Question 3: What are the participants' perceptions on the educational reasons for their failure in learning speaking in English?

In order to explore the learners' perceptions on the educational reasons of their failures in speaking English, 26 items were asked to them. They showed highest positive agreements on the $50^{\text {th }}, 49^{\text {th }}$, and $48^{\text {th }}$ items stating "If much importance had been given on four basic skills (listening, speaking, reading, and writing) in English lessons, I would speak English better." $(69.7 \%$, mean $=4.07, S D=1.113)$, "If speaking had been practiced with the teacher rather than teaching rules, I would speak English better." (69.7\%, mean $=3.93, S D=1.238)$, and "If I had had a greater vocabulary, I would speak English better." $(68.2 \%$, mean $=4.00, S D=1.286)$. As the results indicate, students prefer their English classes to be more focused on four skills than bare rule teaching, and they see the lack speaking practice and vocabulary learning as substantial educational reasons of their failure in improving their oral production skills. Besides these methodological problems, the learners are also not content with the teaching materials which are boring and unappealing to their interests. These can be obviously seen in the high percentages of agreement on the items "If English had been taught with games and enjoyable activities (songs, films etc.), I would speak English better." $(65.2 \%$, mean $=3.78, S D=1.375$ ) and "If reading texts that appeal to everyone (magazines, cartoons, short stories etc.) had been used in lessons instead of boring ones, I would have learnt speaking English better." $(62.1 \%$, mean $=3.75, S D=1.311)$. Finally, they see the scarcity of class hours as a significant reason of their failure, and they agree $62.1 \%$ on the statement "If I had had more hours of English lessons, I would have learnt speaking English better." (mean $=3.54, S D=1.510$ ).

Highest percentages of disagreements were observed for the items of "I lost my desire to learn speaking English as I always got low grades. That's why I could not learn speaking English." $(65.2 \%$, mean $=2.26, S D=1.523)$ and "If my teacher had not always corrected my mistakes, I would have learnt speaking English better." $(62.1 \%$, mean $=2.37, S D=1.333)$. These results suggest that the learners do not have a problem with their desire in learning English and they also do not see error correction as a discouragement for improving their speaking skill.

Research Question 4: Is there any meaningful relationship among the participants' social, personal, and educational reasons and their individual characteristics such as a) parental knowledge of English and b) family income?

In order to see the relationship between the participants' basic demographic information and reasons for failure in speaking English, cross tabulation analysis were conducted.

First of all, the interplay between mother's knowledge of English and item 8 which states that "If there had been English speakers around me, I would have learnt speaking English better." was analyzed. $93.9 \%$ of the participants whose mother cannot speak English strongly agreed on the statement while only $6.1 \%$ of the ones whose mother can speak English strongly agreed on it. It can be inferred that students whose mother cannot speak English believe that their mother's lack of knowledge of English is quite effective on their failure in speaking that language.

Father's knowledge of English, which is another significant variable in this study, was also analyzed to reveal its connections with the $8^{\text {th }}$ item. $90.9 \%$ of the participants whose father cannot speak English reported that they strongly agreed on the statement. However, only $9.1 \%$ of them whose father can speak English strongly agreed on that item. The results suggest that the learners whose father cannot speak English considered their father's lack of that ability as a significant factor influencing their speaking skill negatively.

Finally, the relationship between monthly income of the family and item 15 which states that "To learn speaking English I need to go to language courses but our financial situation was not good. Therefore, I could not learn speaking English." were analyzed through cross tabulation.

$45.5 \%$ of the participants who strongly agreed on the item had a monthly income between 1001 and $3000 \mathrm{TL}, 36.4 \%$ of them had less than $1000 \mathrm{TL}$ of income per month, and $18.2 \%$ had an income more than $6000 \mathrm{TL}$. The findings indicate that majority of the participants who agree on that item are from low income families (with less than $1000 \mathrm{TL}$ or between 1001 
and $3000 \mathrm{TL}$ income) and they perceive the low amount of their family income as a factor negatively influencing their language education and consequently speaking skill.

Semi structured question forms revealed more information regarding personal, social and educational backgrounds of the participants. Half of the participants $(n=4)$ stated that their speaking skills are not enough to continue a conversation. The other half stated that even if they feel that they study a lot, and pass their classes, they are far behind from the point they need to be. Analyzing the data, the researchers find out that the participants do not see themselves as the reason for their failure in speaking English. One of the participants stated that "I cannot speak well because my teachers didn't give enough importance for my English (P2)". Another participant underlines an educational point; emphasis on grammar rather than speaking skills. "I would say: no, I cannot speak English, because it is grammar what is important in schools not speaking $(P 3)$ ". The perception that if teachers emphasize the importance of speaking and give more chance to students to practice, students will feel more secure when they attempt to speak is found out to be one of the main reasons for failure in speaking English. Another finding of the quantitative analysis was also supported by qualitative analysis in terms of students' blaming other factors for their failure in speaking English. Almost all of the participants stated that they follow the classes, learn new words, try to be disciplined language learners, however, they think the problem is somewhere outside than themselves.

From the social perspective, the participants think that English is quite important for their future career, but the teaching environment does not cover the expectations of the society or private sector. "In Turkey, English is taught just to save the day like other things in our country. I learn something one year, forget and start over in the coming year. There is no continuity of the classes (P1)", which was backed up with the opinions of P3 "There is no problem in giving importance. The problem is the wrong education system. We learn English not to speak, but pass the tests". Even if $72.8 \%$ of the participants think that they could speak better if there were English speakers around them, it was found that they do not like the idea of teachers' speaking only English in classes. One of the participants stated "Language becomes more complicated when the teacher always speaks English (P2)".

The participants were asked Q4: Describe your ideal English teacher. Were your teachers like you described? All of the participants $(n=8)$ stated the most important requirement of an English teacher is motivating students. They put communication competences and mastery in the field in number two and three. It is clearly seen that loving a language comes before learning it.

\section{Discussion}

This research study aimed to explore social, personal, and educational reasons for the failures of Turkish EFLlearners in speaking skill. Findings indicated that students consider educational and social reasons as more effective than personal reasons on their inabilities in oral production.

According to the results, the most influential social reasons on the learners' speaking skill were the lack of L2 input from their families, other significant people around them, and the media. It is verified by Işık (2008) and Yurtsever-Bodur(2015) stating that language cannot be learnt without interacting with the social environment; therefore, presence of people who can speak the language and amount of input coming from TV or other information tools are quite substantial in that process. It is also suggested by the results that the participants do not have any nationalistic perspectives on learning L2, which can be attributed to their awareness of the significance of English language in their lives (Yurtsever-Bodur, 2015).

As the findings regarding personal reasons of their failure showed, the students do not tend to blame themselves much about the problem. However, according to Gökdemir (2005), they have highly important roles during the language learning process since it is not possible to do it without their personal effort and investment. Some contradictory results are also available about personal reasons. While quantitative data revealed that half of the participants agree on not spending enough time and effort to learn English, qualitative data showed that all of the participants think they make great effort to learn it and the reasons of failure are not about themselves. It can be speculated based on their contradictory statements that during interviews the participants did not want to lose face and answered in bias, which is a drawback of interviews.

The study explored that the most important reasons for students' failure in speaking English are educational. Unfortunately, language classes in Turkey are mostly based on grammar teaching. However, the participants want to learn how to speak the language rather than only the rules of the language and they wish for more practice in using the language. These findings are supported by many other studies in the literature. Çetintaş (2010) and Haznedar (2010) explain that formfocused instruction which lack any kind of oral production practice is the biggest problem in Turkish EFL classes. Thus, as 
suggested by Aktaş (2005), teachers should encourage the learners for more practice rather than focusing on the structure all the time.In addition, the participants ask for more enjoyable and attractive materials for their interests. The influences of well-designed and appealing course materials on speaking skill are also emphasized and supported by many by research studies in the area (Buyukyavuz and İnal, 2008; Hutchinson, 1987; Kizildag, 2009; YIImaz, 2008). Therefore, it is certain that the materials that are used in EFL classes in Turkey should be revised and updated to be more attractive for the learners and provide more opportunities for speaking practice (Kizildag, 2009; Yılmaz, 2008).

Finally, it was revealed in the study that the students with low-income families see their families' financial situation as an obstacle to their speaking ability because they state that they cannot go to private language courses. That finding is supported by the students' highly strong belief that if they could go abroad, they would learn speaking English much better; but they cannot do that as well due to the same problem. Encouraging the learners to attend projects and activities that are funded by European Council could be a starting point to solve that problem.

\section{Conclusion and Recommendations}

The obstacles of speaking a foreign language may be rooted in many factors; yet this paper deals with personal, social and educational reasons. Though personal reasons are not perceived as significant for their failure in speaking by learners, they need to be studied in terms of motivation, anxiety and barriers for speaking in another language. As this study was conducted with preparatory class students, they may have forgot about the first times they attempted to speak in a foreign language. This makes a further research on students having English classes for the first time more valuable and long-felt need. Societal factors were also addressed as the reasons for failure in speaking English. Most students say that their environment, daily lives, schools or homes lack in providing enough input for them. This can be accepted to a point as for the fact that English is the most widely spoken foreign language in the world. It is easy to access English resources, news, music, magazines or even English speaking people in a very small town in Turkey, which makes practicing it quite flowing. However, students may find the resources expensive to get or they are not aware of accessing resources online. Therefore, teachers' using the IT or other media tools in the classrooms rather than banning them altogether may help for the solution. Third and the most complained title was educational factors; mostly because all of the learners went through the same process, they have common memories about learning a new language. Also, if they attended state schools in Turkey, they were taught the same curriculum with more or less the same methods or teaching techniques. It is an undeniable fact that Turkish education system has some deficits in practice, even though it may seem perfect in its written documents. English teachers mainly focus on grammar, because of central exams students have to take and because of their own failure in speaking English. In order to overcome this difficulty, both students and teachers should participate in projects, and central exams should cover these projects or other tasks requiring speaking skill.

The results show that teacher traning needs noting to be improved. Graduating from universities, teachers -who used to be students just two months ago- pass a test and become teachers, which make their jobs harder as they have to cope with classroom management, school's paper work, supervision, parents, work load and their private lives at the same time. A suggestion for the MoNE can be a 'practicum year' between university and work life, during when the novice teachers can be exchanged and learn about the practices in schools in an English speaking country before representing the language with its culture in class. Accordingly, a further study can be suggested with the teachers employed for the first time, asking their expectations and difficulties they have been through. This research study aimed to pave the way for the further studies for the failure of speaking English in Turkey.

\section{References}

[1] Aktaş, T. (2005). YabancıDilÖğretimindeiletişimsel Yeti. Journal of Language and Linguistic Studies Vol. 1, No.1, 89-99.

[2] Akyel, A. S., \&Ozek, Y. (2010). A language needs analysis research at an English medium university in Turkey. Procedia-Social and Behavioral Sciences, 2(2), 969-975.

[3] Alptekin, C., \& Tatar, S. (2011). Research on foreign language teaching and learning in Turkey (20052009). Language Teaching, 44(03), 328-353.

[4] Aydın, S. (2009). Test anxiety among foreign language learners: A review of literature. Journal of Language and Linguistic Studies, 5(1), pp-127.

[5] Baş, G. (2014). Lise Öğrencilerinde Yabancı Dil Öğrenme Kaygısı: Nitel Bir Araştırma. Pamukkale Üniversitesi Eğitim Fakültesi Dergisi, 36(2), 101-119. 
[6] Büyükyavuz, O., İnal, S. (2008) A Descriptive Study of Turkish Teachers of English Regardşng Their Professional Needs, Efforts for Development and Available Resources. The Asian EFL Journal Quarterly. Volume 10, Issue 3

[7] Çetintaş, B. (2010). Türkiye'de yabancı dil eğitim ve öğretiminin sürekliliği. Journal of language and linguistic studies, 6(1), 65-74.

[8] Dellinger, A. B., Bobbett, J. J., Olivier, D. F., \&Ellett, C. D. (2008). Measuring teachers' self-efficacy beliefs: Development and use of the TEBS-Self. Teaching and Teacher Education, 24(3), 751-766.

[9] Demir, A., Yurtsever, A., \&Çimenli, B. (2015). The Relationship between Tertiary Level EFL Teachers' Selfefficacy and their Willingness to Use Communicative Activities in Speaking. Procedia-Social and Behavioral Sciences, 199, 613-619.

[10] Demir, B. \& I. H. Erten (2005). An investigation into the age factor on the motivation and attitudes of young learners. Paper presented at the 4th International ELT Research Conference, Onsekiz Mart University, Çanakkale, May 2005.

[11] Gardner, R. C. (1985). Social Psychology and second language learning: The role of attitudes and motivation. London: Edward Arnold.

[12] Gökdemir, C. V. (2005). Üniversitelerimizdeverilenyabancıdilöğretimindekibaşarıdurumumuz. Atatürk ÜniversitesiSosyalBilimlerEnstitüsüDergisi, 6(2), 251-264.

[13] Haznedar, B. (2010, November). Türkiye'deyabancıdileğitimi: Reformlar, yönelimlerveöğretmenlerimiz. In International Conference on New Trends in Education and Their Implications, Antalya, Turkey. Retrieved from http://www. iconte. org/FileUpload/ks59689/File/166. pdf.

[14] Hutchinson, T. (1987).English For Specific Purposes. Scotland: CUP.

[15] Işık, A. (2008). YabancıDilEğitimimizdekiYanlışlarNeredenKaynaklanıyor?. Journal of Language and Linguistic Studies, 4(2), pp-15.

[16] İnal, S., Evin, I.., \&Saracaloglu, A. S. (2005). The relation between students' attitudes toward foreign language and foreign language achievement. DilDergisi, 130, 37-52.

[17] Kırkgöz, Y. (2009). Students' and lecturers' perceptions of the effectiveness of foreign language instruction in an English-medium university in Turkey. Teaching in higher education, 14(1), 81-93.

[18] Kızıldağ, Ayşe (2009) Teaching English in Turkey: Dialogues with teachers about the challenges in public primary schools. International Electronic Journal of Elementary Education Vol.1, Issue 3, June, 2009.

[19] Kizildag, A. (2009). Teaching English in Turkey: Dialogues with teachers about the challenges in public primary schools. International Electronic Journal of Elementary Education, 1(3), 188-201.

[20] Öztürk, H. veÇeçen S. (2007). The Effects of Portfolio Keeping on Writing Anxiety of EFL Students, Journal of Language and Linguistic Studies, Vol.3, No.2.

[21] Sevingil, E. (2008). In class and out of class speaking and writing anxiety in L2 among ELT MA students. In D. Koksal\& I. H. Erten (eds.) (2008).

[22] Solak, E., \& Bayar, A. (2015). Current Challenges in English Language Learning in Turkish EFL Context. Online Submission, 2(1), 106-115.

[23] Tosun, C. (2006). Yabancıdilleeğitimsorunu. Journal of Language and Linguistic Studies, 2(1).

[24] Uysal, H. H. (2012). Evaluation of an in-service training program for primary-school language teachers in Turkey. Australian journal of teacher education, 37(7), n7.

[25] West, R. (1994). Needs analysis in language teaching. Language teaching, 27(01), 1-19.

[26] Yılmaz, C. (2008). Evaluating EFL coursebooks with respect to communicative language teaching principles in the Turkish context. In D. Koksal\& I. H. Erten (eds.) (2008).

[27] Yurtsever-Bodur, G. (2015). Why can't We Learn English?: Students' Opinions at Akdenız University. (Unpublished Master's thesis). Akdeniz University, Antalya, Turkey.

[28] Zabardast, S. (2014). Foreign Language Use Anxiety in Teachers'and Students' Attitude. International Journal on New Trends in Education \& their Implications (IJONTE), 5(4).

[29] Zerey, O. G. (2008). The impact of theater production on foreign language speaking anxiety of ELT students. In D. Koksal\& I. H. Erten (eds.) (2008). 